\title{
La enseñanza de refranes en el Español como lengua extranjera
}

\author{
ELE teaching through the use of idioms found in \\ canonical works of Spanish Literature \\ Andréa CESCO* \\ Universidade Federal de Santa Catarina (UFSC)
}

\begin{abstract}
RESUMEN: En este artículo se investiga, comenta y propone el uso de refranes españoles sacados de obras canónicas de la literatura hispánica como una herramienta para la enseñanza del español como lengua extranjera (ELE) a los niveles avanzados en Lengua Española y Literatura. Los refranes comprendidos en nuestro corpus se tomaron del "Sueño de la Muerte" (1621), que forma parte de Sueños y Discursos (1993) de Francisco de Quevedo y Villegas (1580-1645). Se propone, en este artículo, una fusión interdisciplinaria entre la enseñanza de español como lengua extranjera, la enseñanza de literatura y la formación de investigadores. Se divide en tres partes: en primer lugar, se abordan el texto de Quevedo y nuestra selección del corpus; a continuación, hay una explicación histórica y semántica de los lenguajes que allí se encuentran; por fin, se destacan algunas de las posibilidades de investigación que surge de este tipo de enfoque.
\end{abstract}

PALABRAS CLAVE: Refranes. Literatura hispánica. Enseñanza de español.

ABSTRACT: This article investigates, comments on and proposes the use of Spanish idioms taken from canonical works of Spanish Literature as a tool for the teaching of Spanish as a Foreign Language (ELE) to advanced levels in Spanish Language and Literature courses. The idioms comprised in our corpus were taken from "Sueño de la Muerte" (1621), which is part of Sueños y discursos (1993) by Francisco de Quevedo y Villegas (1580-1645). This article proposes an interdisciplinary fusion between ELE teaching, the teaching of Literature and researcher training. It is divided in three parts: first, Quevedo's text and our corpus selection are tackled; then, there is a historical and semantic explanation of the idioms found there; at last, some of the research possibilities emerging from this type of approach are highlighted.

KEYWORDS: Idioms. Spanish literature. Teaching of Spanish.

\section{Introducción}

Este artículo tiene por objetivo investigar, comentar y proponer el uso de refranes sacados de obras canónicas de la literatura hispánica para la enseñanza de español como lengua extranjera en niveles avanzados y en la formación de profesionales de Letras. Se espera con eso que los estudiantes de español puedan no solamente desarrollar su competencia en la lengua a través de la literatura, sino también volverse investigadores de la lengua. Se propone, en otras palabras, una fusión interdisciplinaria entre la enseñanza de español como lengua extranjera, la enseñanza de la literatura y la formación de investigadores.

\footnotetext{
* Doutorado em Literatura; docente da Universidade Federal de Santa Catarina (UFSC), Departamento de Língua e Literatura Estrangeiras e do Programa de Pós-Graduação em Estudos da Tradução. Florianópolis SC - Brasil. Email: andrea.cesco@gmail.com.
} 
La enseñanza de la lengua y la literatura en todos los niveles es un trabajo de comprensión, de producción y de reflexión sobre el uso con textos que desempeñan diferentes funciones comunicativas, en diferentes ámbitos de la interacción social, uno de los cuales es el de comunicación literaria (GONZÁLES NIETO, 2001, p. 337).

Elisabetta Santoro, en su tesis (2007), también propone la integración de la enseñanza de lengua extranjera y de la enseñanza de literatura; defiende la "dilución" de la dicotomía lengua/literatura, ya que las dos se encuentran en el texto literario.

En lo que se refiere al uso de refranes, se justifica por actualizar y revitalizar los componentes culturales de un pueblo, manifestando los elementos característicos de una cultura, de una forma de pensar y vivir, al mismo tiempo en que pone de relieve su relación con las culturas que le son próximas. Ellos encierran valoraciones y juicios sobre comportamientos, reflejan sentimientos y guardan relaciones con la sociedad en que se escriben. Forman parte de la tradición oral de la humanidad y tienen que ver con otras formas de literatura folclórica, como la adivinación y las fábulas. Alcanzan su permanencia en nuestra mente por medio de una cierta configuración poética, o sea, buscando sonoridad, oposiciones, paralelismos, brevedad, elipsis etc.

Los refranes elegidos para componer el corpus analizado fueron sacados del texto "Sueño de la Muerte" (1621), de la obra Sueños y discursos (QUEVEDO Y VILLEGAS, 1993, p. 309-403), de Francisco de Quevedo y Villegas (1580-1645), que forma parte de la literatura canónica española y hace un extenso uso de los refranes. La obra está compuesta por cinco narrativas, ${ }^{1}$ dispuestas en forma de diálogo, que satirizan las costumbres y los personajes de su tiempo, de todas las clases sociales. Su elección se debe, principalmente, al hecho de que son, por consenso universal, los mejores textos en prosa de Quevedo. Su lectura es extremadamente enriquecedora y agradable, destacadamente por dos razones: su propia condición literaria y el retrato que proporciona de la realidad social de España en el siglo XVII. Los textos son creativos en el uso del lenguaje coloquial, de los refranes y expresiones creadas en el cotidiano de un grupo de personas de un lugar y de una época específica. Además, Quevedo es un autor poco explotado académicamente en Brasil.

Este artículo está dividido en tres partes: primero tratamos del texto elegido y de la selección del corpus. Después son enfocados los refranes, tratando de aclarar sus significados por medio de sus historias y, por último, se indican algunas posibilidades de investigación suscitadas por el uso de ese material.

\section{El texto: "Sueño de la muerte"}

Los Sueños, obra escrita entre 1605 y 1621, busca denunciar los abusos, vicios y engaños de todos los oficios y estados del mundo. Sus tipos y figuras son producto de los desengaños que el autor padece en esos años; ellos dicen que no hay nobleza ni verdad en el mundo y que todo es horrible y feo.

La narrativa empieza con la descripción del narrador a respecto de su estado de ánimo deprimido, que le induce a dormir y a soñar con un desfile de gente desaliñada y rota. Todos son "ministros del martirio" e "inducidores de la muerte", porque, como médicos y cirujanos, matan a sus pacientes y porque preceden y anuncian la entrada de la Muerte en persona. Esta se ofrece al narrador como guía en la visita a los muertos en la

\footnotetext{
1 "Sueño del Juicio", “Alguacil endemoniado", "Infierno", "El mundo por de dentro" y "El sueño de la Muerte".
} 
ultratumba. $^{2}$ Él acepta y la sigue en su tribunal y audiencia. Los muertos -figuras simbólicas que encarnan refranes o dichos populares- se acercan al narrador uno tras otro para quejarse de la forma como son tratados por los hombres en el mundo. Quevedo personifica a estas figuras y permite que protesten contra sus circunstancias.

De los treinta refranes encontrados en este texto, cinco fueron elegidos para componer el corpus. Eso se dio, principalmente, por la necesidad de reducir el número de refranes, ya que se trata de un artículo, y por creer que la elección de una "muestra representativa" serviría para inferir el valor del conjunto. Así, el criterio establecido para elegir esta muestra representativa fue de que se enfocarían los refranes con el origen histórico mejor documentado. Se trata de aclarar sus significados por medio de su historia, pues del refrán "se desprende una consecuencia práctica de orden moral o de conducta" (MALDONADO, 1990, p. 08).

\section{Los refranes seleccionados}

Y luego ensartar nombres de simples, que parecen invocaciones de demonios: Buphthalmus, Opopanax, Leontopetalum, [...]. Y sabido qué quiere decir esta espantosa baraúnda de voces tan rellenas de letrones, son zanahorias, rábanos, perejil y otras suciedades, y como han oído decir, "Quien no te conoce te compre", disfrazan las legumbres por que no sean conocidas y las compren los enfermos (QUEVEDO Y VILLEGAS, 1993, p. 322-3).

Quevedo utiliza ese refrán, que remonta a la Edad Media y era común también en el Renacimiento, para hablar mal de los boticarios, criticando nombres poco comunes y complicados que ponen en las recetas, como señal de sabiduría, dando una impresión de eficacia, indicando que el producto que allí se encuentra es raro y difícil de ser encontrado, disfrazando así productos de uso cotidiano. En varios pasajes es acusado de proporcionar armas mortales a los médicos.

En cuanto a la expresión, El Diccionario de Autoridades, de $1729,{ }^{3}$ así explica: "fe fuele ufar para dar à entender que fe ha conocido el engaño que fe venia à executar". 4 Campos y Barella (1993, p. 104), así como Junceda (2006, p. 409), dicen que "los defectos de las personas o de las cosas no suelen ser evidentes a primera vista. Denota haberse conocido el engaño o malicia de alguno". En portugués encontramos su equivalencia exacta, de forma y significado, en "quem não te conhece que te compre", como "uma expressão irônica em que se faz sentir o conhecimento das manhas de certa pessoa ou de suas intenções" (CABRAL, 1982, p. 243).

Buitrago, en el Diccionario de dichos y frases hechas (2006, p. 614), agrega que con este dicho popular afirmamos conocer perfectamente los aspectos negativos de una persona $\mathrm{y}$, al mismo tiempo, nos mostramos resistentes a establecer relaciones con ella porque desconfiamos de su comportamiento.

\footnotetext{
${ }^{2}$ Así como Virgilio que sirvió de guía a Dante en La Divina Comedia.

${ }^{3}$ Nuevo Tesoro Lexicográfico de la Lengua Española. http://buscon.rae.es/ntlle/SrvltGUILoginNtlle

${ }^{4}$ Se optó por mantener la ortografía de la época, incluso con letras y acentuación actualmente en desuso (I/ à).
} 
Y es de advertir que en todos los oficios, artes y estados se ha introducido el don: en hidalgos, en villanos, en frailes, como se ve en la cartuja. Yo he visto sastres y albañiles con don, y ladrones y galeotes en galeras; pues si se mira por las ciencias, clérigos millones, teólogos, muchos letrados. Solos los médicos ninguno ha habido con don, y todos tienen don de matar, y quieren más dan al despedirse que don al llamarlos (QUEVEDO Y VILLEGAS, 1993, p. 332).

Dando continuidad a la sátira de los médicos, en la segunda mitad del siglo XVI el título de 'don' empezó a extenderse a toda la clase media, lo que era motivo de burla entre los satíricos; abundaban los chistes a base de don, dan y din. El trecho destacado hace alusión al dicho popular "Mucho don y/pero poco din" que se refiere a la persona que aparenta lo que no tiene. La duplicidad de significados, mediante el juego de palabras es explotada, pues el "don" tanto se refiere al título nobiliario como la habilidad que alguien tiene para hacer algo, y en este caso se apunta al "don" que el médico tiene de matar. Además de esa duplicidad, juega también con una tercera palabra: "dan", que se refiere al "din", ruido que hacen las monedas cuando se tocan, pues para los médicos importa más el "din" en el bolsillo que el "don" en el nombre.

Según Buitrago (2006, p. 492-3) es "hacer ostentación de una elevada posición social o económica que en realidad no son tales". Explica aún que la frase se aplicó en sus orígenes a aquellos supuestos hidalgos o caballeros, tan en boga durante los siglos XVI y XVII, que aparentaban mucha honra y extravagancia, mucho don, y que no tenían ninguna plata. En portugués diríamos algo como "muito fricote para pouco dote" o entonces "comer sardinha e arrotar caviar", que es dicho de la persona que intenta parecer lo que no es.

\begin{abstract}
Yo soy -dijo- el Rey que rabió, y si no me conocéis, por lo menos no podéis dejar de acordaros de mí, porque sois los vivos tan endiablados que a todo decís que se acuerda del Rey que rabió. En viendo un paredón viejo, un muro caído, una gorra calva, un ferreruelo lampiño, un vestido caduco, una mujer manida de años y rellena de siglos, luego decís que se acuerda del Rey que rabió (QUEVEDO Y VILLEGAS, 1993, p. 344).
\end{abstract}

De acuerdo con el Diccionario de Autoridades, de 1737, ese dicho popular se refiere a las cosas muy viejas o antiguas. Correas incluye una variante: "El rey que rabió; y llevaba la manta arrastrando", o entonces "Acuérdase del rey que rabió", para decir que además de muy vieja o antigua, principalmente es pasada de moda (1992, p. 183).

Buitrago (2006, p. 287) agrega que esa expresión se hizo popular gracias a una famosa zarzuela, El rey que rabió, que estrenó en 1891. En portugués, para afirmar que algo es pasado de moda o muy antiguo se utilizan expresiones tales como: "Isso é do tempo do Ari Pistola" (o Ariri Pistola), "Isso é do tempo do Êpa", 6 "Isso é do tempo da minha vó" o aún "Do tempo do guaraná de rolha".

\footnotetext{
${ }^{5}$ Hay una canción popular que dice "Eu vou contar pra vocês versinhos que são de escola, versinhos do Ariri Pistola", del trío "Os três xirus", Bruno Neher, Elmo Neher y Jorge Fagundes.

${ }^{6}$ Viene de "Epaminondas", que por ser un nombre muy antiguo está en desuso.
} 
Pues los maridos (porque tratamos de honras) considero yo que andarán hechos buhoneros de sus mujeres, alabando cada uno sus agujas (QUEVEDO Y VILLEGAS, 1993, p. 353).

Un tipo frecuente de personaje en la literatura es el del esposo consentido o "maridillo" (no marido sino cornudo), por debilidad, desvergüenza o negocio. El tema de los cornudos alcanza todos los ámbitos de la sociedad española del Siglo de Oro, desde los más cultos a los más populares. "Baste repasar los numerosos refranes relacionados con este argumento en el Vocabulario de Correas, o recordar los protagonistas del Lazarillo de Tormes o del Guzmán de Alfarache y el provecho que sacan de sus matrimonios" (CACHO CASAL, 2003, p. 168).

Quevedo alude a la honra del cornudo porque éste comercializa a su propia mujer y transforma su situación en un oficio, como si fuera un alcahuete. Hay dos maneras en los Sueños en que el cornudo consentido se vuelve ignorante: cuando tiene promesa de dinero y de comida por parte del amante o cuando sabe que su mujer recibirá "visita". En este caso el marido sale de casa y al regresar, para avisar que se está aproximando de la casa, avisa a los dos con una fuerte tosidura. Otra mención que hace es que es evidente que el cornudo voluntario prefiere, para su propio bien, que su mujer se venda a los ricos que a los pobres.

Quevedo parodia el refrán "Cada buhonero alaba sus agujas", exactamente porque hace alusión al marido cornudo. Junceda (2006, p. 94), con una variante, "Cada ollero alaba su puchero", comenta que ese refrán da a entender que cada uno piensa siempre que lo suyo es lo mejor. Campos (1993, p. 55) dice que los buenos vendedores saben hacer propaganda de su mercancía presentándola como la mejor.

Y estoy rogando con mi persona al purgatorio, y todas las almas dicen en viéndome: "Dueña, no por mi casa". Con el cielo no quiero nada, que las dueñas en no habiendo a quién atormentar y un poco de chisme, perecemos. Los muertos también se quejan de que no los dejo ser muertos como lo habían de ser, y todos me han dejado en mi albedrío si quiero ser dueña en el mundo. Más quiero estarme aquí por servir de fantasma, que en mi estrado toda la vida, sentada a la orilla de una tarima guardando doncellas, que son más de trabajo que de guardar. (QUEVEDO Y VILLEGAS, 1993, p. 377).

Ese dicho es una parodia del refrán tradicional: “¡Justicia, no por mi casa!”, y según Fernández (1994, p. 150), este refrán enseña que todos desean que los delitos sean castigados, pero no cuando ellos mismos son los culpables. Según Junceda, ese refrán "dícese por ironía, en cuanto propugna el rigor para los demás y la blandura para uno", pero más considerada es esa variación: "Justicia, Dios la conserve, pero de ella nos preserve" (2006, p. 230). Lacerda da tres variantes equivalentes de ese refrán en portugués: "A justiça a todos guarda, mas ninguém a quer em casa", "Justiça na sua porta não há quem queira", "Todo o mundo quer justiça mas não em sua casa" (1999, p. 187).

En cuanto a la palabra dueña encontrada en ese refrán, ella es presencia constante en las sátiras de Quevedo. Así era llamada, en español medieval, una mujer que no era doncella, y según el Diccionario de Autoridades, de 1732, esta es una mujer viuda o de repecto que, para autoridad y guardia de las demás criadas, hay en las casas de señores y palacios. Deleito y Piñuela, comentando sobre su aspecto, dice que tenía "arrugado semblante y negras y reverendas tocas, que ayudaban a las jóvenes en sus labores 
domésticas, y eran guardianes de su recato o cómplices de sus galanteos. Algunas eran señoras empobrecidas o viudas con pretensiones hidalgas" (1966, p. 131-132).

El origen de la vieja dama codiciosa que resultaría en la "dueña" quevedesca deriva probablemente de la figura popular de la "viuda alegre", que busca más que todo la buena vida y su propio lucro.

\section{Lengua y literatura: el estudiante como investigador}

La principal ventaja del uso de textos literarios (en particular los textos literarios antiguos), para la enseñanza de lengua extranjera, es incitar en los alumnos la práctica de la investigación, dándoles aporte en la comprensión de lectura, tanto de obras clásicas como modernas (recordando que el alumno en cuestión es un académico de Letras). Esta práctica investigativa puede concretizarse de diversas formas.

En el caso de los refranes, la posibilidad más evidente es establecer sincrónicamente sus significados en el contexto de la época y diacrónicamente los cambios que puedan o no haber sufrido en la parte semántica o sintáctica. La primera necesidad que sugiere es la investigación en diccionarios especializados, tanto antiguos como modernos, por la presencia de léxico inhabitual y por las transformaciones que a veces los refranes hacen sufrir a las palabras. A partir de ahí (como más adelante veremos) también se podrá: verificar las correspondencias de un mismo refrán en las dos lenguas (español y portugués); investigar cómo son utilizados los modos y tiempos verbales, incluso los ya en desuso; profundizar la consciencia histórica de los estudiantes.

Para ejemplificar la primera posibilidad - los cambios que el refrán pueda o no haber sufrido con el tiempo -, presentamos una investigación diacrónica en el diccionario sugerido anteriormente, de 1737 hasta la actualidad. Para eso elegimos de forma aleatoria "el rey que rabió", ya mencionado anteriormente.

Encontramos su significado en el Diccionario de Autoridades de 1737 (buscando en la entrada "rabiar"), escrito con algunos signos gráficos distintos de hoy, incluso acento grave, ya en desuso. Además, el refrán va acompañado de su correspondiente en latín y de un ejemplo en la literatura de la época.

Figura 1 - Entrada del Diccionario de Autoridades de 1737

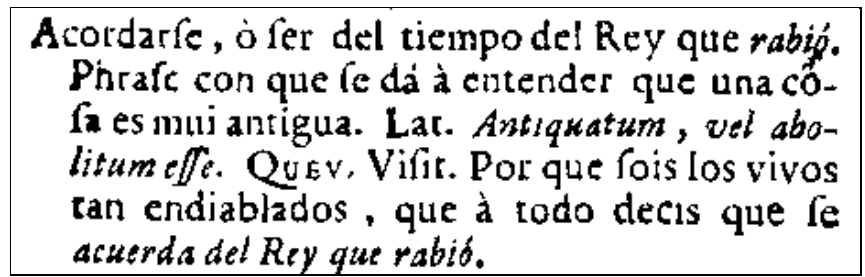

(Fonte: NTLLE, 1737, p. 479,1)

Sin embargo, en las dos entradas siguientes, de 1780 y 1803 , que ya pertenecen a la Academia Usual o no más al Diccionario de Autoridades, se perciben cambios en el alfabeto español y que el ejemplo que había en el anterior ha sido excluido. El acento grave también es sustituido ahora por el agudo. En la segunda entrada el verbo "acordarse" es eliminado y hay una nueva variante para el mismo refrán, "del rey que rabió por gachas. Pero ésta es la última vez que el refrán aparece en esta entrada, "rabiar". 
Figura 2 - Entrada de la Academia Usual de 1780

ACORdarse, 6 SER DBL TIEMPO DEL RBY QUE
Rabió. f. fam. con que se da á entender que una
cosa es muy antigua. Antiquatum, vel abolitum
esse.

(Fonte: NTLLE, 1780, p. 773, 2)

Figura 3 - Entrada de la Academia Usual de 1803

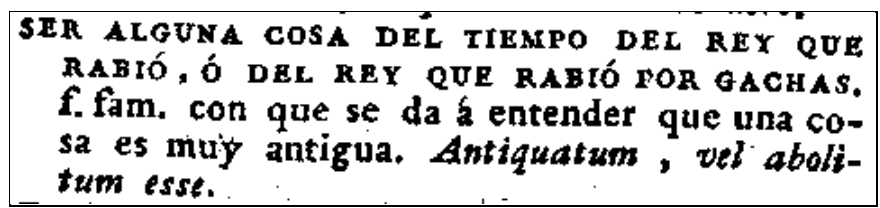

(Fonte: NTLLE, 1803, p. 711, 1)

De forma mucho más explicativa que en las entradas anteriores, y después de un gran hiato, el refrán vuelve a aparecer en este diccionario, en la entrada "rey", en 1884. Incluso, vuelve el verbo "acordarse" en el ejemplo. Otras dos informaciones que difieren de la anterior es que la cosa de que se habla pasa de "muy antigua" para "antigüedad muy remota"y su correspondiente en latín desaparece.

Figura 4 - Entrada de la Academia Usual de 1884

meros reyes que salgan.||El rey que ra-
bió, ó el rey que rabio por gachas. Per-
sonaje proverbial, símbolo de antigüedad
muy remota. Empléase generalmente en
las frases: Acordarse DEL REY QUE RABIó
ser del tiempo DEL REY QU RABIó, DEL REY
QUE RABtó POn GACHAS.|| La del rey. loc.

(Fonte: NTLLE, 1884, p. 934, 1)

En la entrada de 1914 no encontramos cambios en el refrán, sólo en la lengua. En la penúltima línea, el acento agudo en la conjunción "ó" no existe más. Ya en las entradas de 1925 y 1936 se agrega una nueva variante del refrán: "en tiempo del rey Perico. Además, en 1936 se agrega "el rey que rabió por gachas, o por sopas", pero el significado sigue igual.

Figura 5 - Entrada de la Academia Usual de 1914 meros reyés que salgan. „| El rey que rabló, o el rey que rabio por gachas. Personaje proverbial, simbolo de antigiiedad muy remota. Empléase generaimente en las frases acordarse DEL REY QUE RABIÓ; ser del tiempo DEL REY QUE RABIó, $O$ DEL REY QUE RABIó POR GACHAS. || Hacer el rey consulta. fr. ant.

(Fonte: NTLLE, 1914, p. 898, 1) 
Figura 6 - Entrada de la Academia Usual de 1925

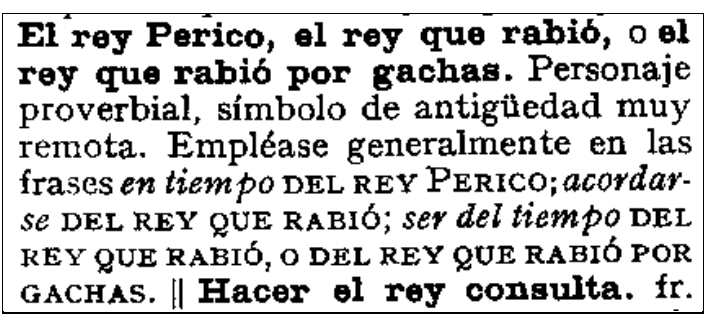

(Fonte: NTLLE, 1925, p. 1061, 1)

Figura 7 - Entrada de la Academia Usual de 1936

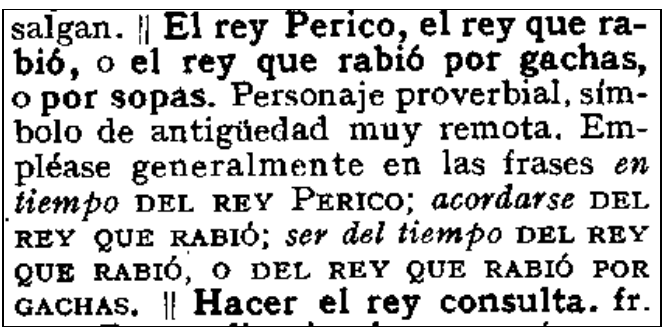

(Fonte: NTLLE, 1936, p. 1106, 2)

Actualmente, en el Diccionario de la Real Academia, online, vigésima segunda edición, ${ }^{7}$ el refrán se mantiene: "el rey Perico" o "el rey que rabió", o "el rey que rabió por gachas", o "el rey que rabió por sopas". "Personaje proverbial, símbolo de antigüedad muy remota. En tiempo del rey Perico, Acordarse del rey que rabió, o del rey que rabió por gachas".

En el caso de este refrán investigado, uno se da cuenta que pasados tres siglos no hubo cambios semánticos, sino algunos cambios de ortografía. Además, nuevos elementos fueron agregados al refrán, que sigue presente hasta hoy.

Como segunda posibilidad de investigación, se podrán destacar las correspondencias de un mismo refrán en las dos lenguas (español y portugués), analizando diferencias y semejanzas. Explotar las posibles explicaciones para las diferencias encontradas (geográficas, de influencia histórica, de sonoridad). Como ejemplo de refrán absolutamente igual en las dos lenguas, cito "Quien no te conoce te compre". En portugués el sentido es igual al español y su sonoridad se mantiene por ser también bimembre. Como ejemplo de las diferencias tenemos "Acordarse o ser del tiempo del Rey que rabió". En portugués, la correspondencia se apoya solamente en lo que quiere decir este refrán, a qué se refiere. Ahí lo adaptamos a nuestra realidad: "Ser do tempo do Ari Pistola; do Êpa; do guaraná de rolha".

Importante aquí, en esa posibilidad de explotación, según Peñate Rivero (1995, p. 292), no es "desentrañar la verdad sino la producción lingüística y la tomada de consciencia de un substrato cultural común (teniendo en cuenta que el refrán nos llegó a través del griego y del latín)". Y agrega que cuando no se consigue identificar el refrán adecuado o que se acerque, esta carencia puede resultar pedagógicamente rentable:

\footnotetext{
${ }^{7}$ http://www.rae.es/rae.html
} 


\begin{abstract}
La ausencia de una versión más o menos "canónica" dará lugar a la discusión sobre el sentido del refrán en la lengua de origen, estimulará la aparición de varias correspondencias y la reflexión común sobre sus ventajas e inconvenientes e incluso facilitará la controversia sobre la conveniencia de buscar una traducción literal, de la supresión pura y simple del refrán, del recurso a la explicación a pie de página, etc. El intercambio aquí importa tanto o más que la solución (PEÑATE RIVERO, 1995, p. 292).
\end{abstract}

Como tercera posibilidad, se puede explotar los refranes gramaticalmente, por ejemplo, a partir de los verbos, para que los identifiquen y reflexionen sobre ellos.

Como cuarta posibilidad, se propone trabajar con seminarios, señalando algunos temas atractivos relativos a aquella época y que generan la discusión, como el hombre, la mujer, la sociedad, la realeza, las profesiones, el clero, la moralidad, el honor, la hipocresía, la justicia y otros. Esa actividad exigirá una profunda investigación, tanto en los diccionarios como en los libros de historia. Como ejemplo, se cita el refrán "mucho don y/pero poco din", visto anteriormente

Se dijo anteriormente que este refrán tiene que ver, en el texto de Quevedo, con la sátira de los médicos. Pero, hay mucho más que investigar, por ejemplo, sobre la sociedad y las desigualdades en España en la época de Felipe IV, sobre los títulos nobiliarios que ese rey concedió a muchas personas de la nobleza, sobre los caballeros e hidalgos, nobles de categoría inferior. Es fundamental explotar la historia de la sociedad y de todos los personajes y temas que forman parte de ella, pues con eso se agregan conocimientos que enriquecen las lecturas de obras de esa época y confluyen también en la comprensión de los refranes, además, toda esa investigación resultará también en una ampliación de la competencia lingüística.

No se quiere aquí limitar las posibilidades solamente a las trabajadas, sino que éstas sirvan como ideas y sean el principio para otras tantas posibilidades que puedan brotar de este rico material que es el refrán.

\title{
Conclusión
}

Resaltamos y ratificamos, para concluir, que se espera que los alumnos, a partir de los textos literarios, y más precisamente del refrán, tan poco trabajado en clases tanto de literatura como de lengua, puedan no solamente desarrollar la competencia en la lengua, sino volverse investigadores de la lengua. Así como Santoro sostiene (2007), se espera también que puedan leer de forma más autónoma y productiva y que tengan estímulos para reflexionar más sobre el lenguaje y su complexidad. Además, con el tiempo, se espera que ellos se vuelvan menos ingenuos y más preparados receptores y productores de textos. Pues cuando se estudia un texto literario, se estudia también las manifestaciones culturales de un país.

Em suma, a "abertura" do texto literário o torna passível de várias manipulações. Caberá ao professor, em parceria com os alunos, trazer à tona as múltiplas virtualidades que ele oferece para fins pedagógicos quando estão em foco a língua e/ou a literatura (CAMORLINGA ALCARAZ, 2002, p. 322). 


\section{REFERENCIAS}

BUITRAGO JIMÉNEZ, A. Diccionario de dichos y frases hechas. 13. ed. Madrid: Espasa, 2006.

CABRAL, T.. Novo dicionário de termos e expressões populares. Fortaleza: UFC, 1982.

CACHO CASAL, R.. La poesía burlesca de Quevedo y sus modelos italianos. Santiago de Compostela: Universidad de Santiago de Compostela, 2003.

CAMORLINGA ALCARAZ, R.. Língua e Literatura: duas faces da mesma moeda. In: Línguas: ensino e ações. Florianópolis: NUSPPLE. LLE, 2002, p. 309-326.

CAMPOS, J. G.; BARELLA, A.. Diccionario de Refranes. Madrid: Espasa-Calpe, 1993.

CORREAS, G. Vocabulario de refranes y frases proverbiales. Madrid: Visor, 1992.

DELEITO Y PIÑUELA, J.. La mujer, la casa y la moda: en la España del Rey Poeta). Madrid: Espasa-Calpe, 1966.

FERNÁNDEZ, M.. Diccionario de Refranes. Madrid: Alderaban, 1994.

GONZÁLES NIETO, L.. Teoría lingüística y enseñanza de la lengua: lingüística para profesores. Madrid: Cátedra, 2001.

JUNCEDA, L. Diccionario de refranes. 7. ed. Prólogo de Gonzalo Torrente Ballester. Madrid: Espasa, 2006.

LACERDA, R. C. de; LACERDA, H. da R. C. de; ABREU, E. dos S.. Dicionário de provérbios: francês - português - inglês. Rio de Janeiro: Lacerda, 1999.

MALDONADO, F. C. R.. Refranero Clásico Español. Madrid: Taurus, 1990.

PEÑATE RIVERO, J.. El refrán en la enseñanza del español lengua extranjera: dime tus refranes y te diré quién eres. In: Actas da ASELE, 6., 1995, p. 289-295. Disponível em: <http://cvc.cervantes.es/ensenanza/biblioteca_ele/asele/pdf/06/06_0288.pdf〉. Acceso en: 05 feb. 2009.

QUEVEDO Y VILlEGAS, F. de. Sueños y Discursos. Edição anotada de James O. Crosby. Madrid: Castalia, 1993.

Nuevo tesoro lexicográfico de la Lengua española. Real Academia Española, Diccionario de la lengua española. Madrid: Real Académica, 1737, tomo 5, p.479,1, parte 1. Disponible en: http://ntlle.rae.es/ntlle/SrvltGUILoginNtlle. Acceso en: 15 jul. 2011.

Nuevo tesoro lexicográfico de la Lengua española. Real Academia Española. Diccionario de la lengua española. Madrid: Joachín Ibarra, 1780, p.773, 2. Tomo único. Disponible en: http://ntlle.rae.es/ntlle/SrvltGUILoginNtlle. Acceso en: 15 jul. 2011.

Nuevo tesoro lexicográfico de la Lengua española. Real Academia Española. Diccionario de la lengua española. 4. ed. Madrid: Viuda de Ibarra, 1803, p. 711, 1. Tomo único. Disponible en:< http://ntlle.rae.es/ntlle/SrvltGUILoginNtlle>. Acceso en 15 jul. 2011

Nuevo tesoro lexicográfico de la Lengua española. Real Academia Española. Diccionario de la lengua española. 12. ed. Madrid: D. G. Hernando, 1884, p. 934, 1. Disponible en:< http://ntlle.rae.es/ntlle/SrvltGUILoginNtlle>. Acceso en 15 jul. 2011. 
Nuevo tesoro lexicográfico de la Lengua española. Real Academia Española. Diccionario de la lengua española. 14. ed. Madrid: Hernando, 1914, p. 898, 1. Disponible en:< http://ntlle.rae.es/ntlle/SrvltGUILoginNtlle>. Acceso en 15 jul. 2011.

Nuevo tesoro lexicográfico de la Lengua española. Real Academia Española. Diccionario de la lengua española. 15. ed. Madrid: Calpe, 1925, p. 1061,1. Disponible en: <http://ntlle.rae.es/ntlle/SrvltGUILoginNtlle>. Acceso en: 15 jul. 2011.

Nuevo tesoro lexicográfico de la Lengua española. Real Academia Española. Diccionario de la lengua española. 16. ed. Madrid: Espasa-Calpe, 1936, 1106,2. Disponible en: <http://ntlle.rae.es/ntlle/SrvltGUILoginNtlle>. Acceso en: 15 jul. 2011.

SANTORO, E.. Da indissociabilidade entre o ensino de língua e de literatura: uma proposta para o ensino do italiano como língua estrangeira. 355f. Tese (Doutorado em Linguística) - Universidade de São Paulo, Faculdade de Filosofia, Letras e Ciências Humanas. São Paulo, 2007.

Recebido em setembro de 2011.

Aprovado em outubro de 2012. 